\title{
Cross-Protective Shigella Whole-Cell Vaccine With a Truncated O-Polysaccharide Chain
}

\author{
Min Jung Kim ${ }^{1,2}$, Young-hye Moon ${ }^{1}$, Heejoo Kim ${ }^{1}$, Semi Rho ${ }^{1}$, Young Kee Shin ${ }^{2}$, \\ Manki Song ${ }^{1}$, Richard Walker ${ }^{3}$, Cecil Czerkinsky ${ }^{1,4}$, Dong Wook Kim ${ }^{1 * t}$ and Jae-Ouk Kim ${ }^{1 *}$ \\ ${ }^{1}$ Clinical Research Lab, International Vaccine Institute, Seoul National University Research Park, Seoul, South Korea, \\ ${ }^{2}$ Laboratory of Molecular Pathology and Cancer Genomics, College of Pharmacy, Seoul National University, Seoul, South \\ Korea, ${ }^{3}$ PATH, Washington, DC, United States, ${ }^{4}$ Institut de Pharmacologie Moléculaire \& Cellulaire, \\ CNRS-INSERM-University of Nice Sophia Antipolis, Valbonne, France
}

OPEN ACCESS

Edited by:

Leonard Peruski,

Centers for Disease Control and

Prevention (CDC), United States

Reviewed by:

Ricardo Wagner Portela,

Universidade Federal da Bahia, Brazil

Marie-Lise Gougeon,

Institut Pasteur, France

William D. Picking,

University of Kansas, United States

*Correspondence:

Dong Wook Kim

dongwook@hanyang.ac.kr

Jae-Ouk Kim

jokim@ivi.int

${ }^{\dagger}$ Present Address: Dong Wook Kim,

College of Pharmacy, Hanyang

University, Ansan, South Korea

Specialty section:

This article was submitted to

Infectious Diseases,

a section of the journal

Frontiers in Microbiology

Received: 23 May 2018

Accepted: 12 October 2018

Published: 31 October 2018

Citation:

Kim MJ, Moon YH, Kim H, Rho S,

Shin YK, Song M, Walker R,

Czerkinsky C, Kim DW and Kim JO

(2018) Cross-Protective Shigella

Whole-Cell Vaccine With a Truncated

O-Polysaccharide Chain.

Front. Microbiol. 9:2609.

doi: 10.3389/fmicb.2018.02609
Shigella is a highly prevalent bacterium causing acute diarrhea and dysentery in developing countries. Shigella infections are treated with antibiotics but Shigellae are increasingly resistant to these drugs. Vaccination can be a countermeasure against emerging antibiotic-resistant shigellosis. Because of the structural variability in Shigellae O-antigen polysaccharides (Oag), cross-protective Shigella vaccines cannot be derived from single serotype-specific Oag. We created an attenuated Shigella flexneri 2a strain with one rather than multiple Oag units by disrupting the Oag polymerase gene $(\Delta w z y)$, which broadened protective immunogenicity by exposing conserved surface proteins. Inactivated $\Delta w z y$ mutant cells combined with Escherichia coli double mutant $\mathrm{LT}(\mathrm{R} 192 \mathrm{G} / \mathrm{L} 211 \mathrm{~A})$ as adjuvant, induced potent antibody responses to outer membrane protein PSSP-1, and type III secretion system proteins IpaB and IpaC. Intranasal immunization with the vaccine preparation elicited cross-protective immunity against S. flexneri 2a, S. flexneri 3a, S. flexneri 6, and Shigella sonnei in a mouse pneumonia model. Thus, $S$. flexneri 2a $\Delta w z y$ represents a promising candidate strain for a universal Shigella vaccine.

Keywords: Shigella, vaccine, O-antigen polymerase, cross-protection, conserved surface proteins

\section{INTRODUCTION}

Shigellosis is one of the major enteric pathogens and is globally associated with 164,300 diarrheal deaths in all age groups including 54,900 diarrheal deaths in children younger than 5 years (Lozano et al., 2012; Liu et al., 2016; Hosangadi et al., 2018). In addition, it is responsible for long-term health and cognitive defects associated with stunting (Niehaus et al., 2002; Guerrant et al., 2008; Walker, 2015). In spite of its importance, a licensed vaccine to protect against this pathogen has remained an elusive goal.

There are four species, Shigella flexneri, Shigella dysenteriae, Shigella sonnei, and Shigella boydii, and more than 50 serotypes of Shigella; 16 serotypes for S. flexneri, 1 serotype for S. sonnei, 19 serotypes for S. boydii, and 15 serotypes for S. dysenteriae (Barry et al., 2013). S. flexneri is the most frequently isolated species worldwide, accounting for most cases in the least-developed countries, whereas $S$. sonnei is more common in low- and middle-income countries. Among these, $S$. flexneri 2a, 3a, 6, and S. sonnei together cover about $80 \%$ of the strains causing shigellosis (Mani et al., 2016). Antibiotics can effectively treat shigellosis but the emergence of antibiotic resistance makes 
the development of a Shigella vaccine a public health priority. Therefore, the World Health Organization has made the development of an effective Shigella vaccine a top priority (Von Seidlein et al., 2006; Ouyang-Latimer et al., 2011; Tribble, 2017).

Lipopolysaccharide (LPS) is a major surface antigen in gramnegative bacteria that has been the target for Shigella vaccine development (Morona et al., 2003; Camacho et al., 2013). LPS consists of three domains: lipid A, the hydrophobic anchor; core oligosaccharides, a non-repeating oligosaccharide domain; and O-antigen (Oag) chains, an oligosaccharide repeat domain (Jann et al., 1982). The structural variability of the Oag chain among serotypes makes it difficult to utilize serotype-specific LPS as a cross-protective agent in shigellosis vaccine. As a result, most previous attempts to make a Shigella vaccine have relied on serotype specific immunity involving four Oag components.

Evidence for masking of Shigella surface proteins is provided by our studies of pan Shigella surface protein-1 (PSSP-1) the C-terminal half-polypeptide of IcsP (Fukuda et al., 1995) that is conserved across Shigella species (Kim et al., 2015). We found that PSSP-1-specific antibodies did not bind IcsP on Shigella cells, which was consistent with another report that LPS Oag of gram-negative bacteria masks other surface antigens, such as IcsP (S. flexneri), by preventing antibody access (van der Ley et al., 1986; Tran et al., 2013).

We sought to develop a simple but broadly protective Shigella vaccine by exploiting conserved Shigella antigens normally masked by LPS O-polysaccharide chains. A new paradigm based on serotype-independent antigens could yield protection across species and serotypes. Although many antigens on the bacterial membrane could potentially contribute to the development of a vaccine, only a few have been explored as vaccine candidates. We identified PSSP-1 which is found on the surface of all Shigellae, but is largely masked by the O-PS chains. In the purified form, this antigen provided serotype-independent protection in mice against all major species of Shigella (Kim et al., 2015). Invasion plasmid antigens IpaB and IpaD, necessary for cellular invasion processes, have been tested as vaccine candidates and both homologous and heterologous protection similar to that seen with PSSP-1 was found (Heine et al., 2014).

We hypothesized that conserved outer membrane proteinspecific antibodies may react to or neutralize Shigella during cell division stages when less or shorter LPS is displayed on the bacterial surface (West et al., 2005). Because Oag chain synthesis depends on the gene products of $w z y$ (Oag polymerase), wzz (Oag chain regulator), and $w z x$ (putative Oag flippase; Raetz and Whitfield, 2002; Valvano, 2003), we constructed LPS-truncated $S$. flexneri 2 a strain by $w z y$ gene disruption $(\Delta w z y)$ to potentially enhance the immunogenicity of conserved outer membrane proteins. In this study, we conducted a preliminary investigation to determine the feasibility of using the S. flexneri 2 a $\Delta w z y$ strain

\footnotetext{
Abbreviations: ASC, antibody-secreting cell; BAL, bronchoalveolar lavage; cfu, colony forming units; dmLT, double mutant LT(R192G/L211A) of heat-labile toxin of Escherichia coli; ELISA, enzyme-linked immunosorbent assay; ELISPOT, enzyme-linked immunosorbent spot assay; F.I., formalin-inactivated; HRP, horseradish peroxidase; $\mathrm{Km}^{\mathrm{R}}$, kanamycin resistance; LPS, lipopolysaccharide; Oag, O-antigen; PSSP-1, pan-Shigella surface protein; RT, room temperature; WT, wild type.
}

as a universal Shigella vaccine candidate. We demonstrated that a preparation of killed $S$. flexneri 2a $\Delta w z y$ cells combined with an adjuvant, the double mutant LT(R192G/L211A) of heat-labile toxin of Escherichia coli (dmLT; Leach et al., 2012), induced strong cross-serotype protective immunity against $S$. flexneri $2 \mathrm{a}$, $3 \mathrm{a}, 6$, and $S$. sonnei in a mouse pneumonia model. This protection was associated with a more pronounced immune response to surface proteins and this response was often augmented in the presence of dmLT.

\section{MATERIALS AND METHODS}

\section{Animals}

Six-week-old female BALB/c mice (Orient Bio, Seongnam, South Korea) and 3-week-old female guinea pigs (Koatech, PyeongTaek, South Korea) were obtained and housed in the Animal Research Facility, International Vaccine Institute (Seoul, South Korea) under standard laboratory conditions. Animal protocols were approved by the Institutional Animal Care and Use Committees of the International Vaccine Institute (No. 2014005).

\section{Construction of Mutant $\Delta \boldsymbol{w z y}$}

S. flexneri 2a 2457T $\Delta w z y$ strain was constructed by $\lambda$ Red recombineering (Datsenko and Wanner, 2000; Ranallo et al., 2006). Briefly, S. flexneri 2a 2457T cells carrying pKD20 (Red recombinase expression plasmid) were cultured in medium with ampicillin and L-arabinose at $30^{\circ} \mathrm{C}$ for electroporation. PCR product was generated using $\mathrm{pKD} 4$ as template, which contains kanamycin resistance $\left(\mathrm{Km}^{\mathrm{R}}\right)$ gene flanked by FRT sites. The primers have $\sim 50$ bp of homology to the $w z y$ gene and the priming sites from pKD4. PCR primer sequences are as follows: 5'-TTATTTTGC TCCAGAAGTGAGGTTATTACTAATTTGGATATTTTC TATAGAGTGTAGGCTGGAGCTGCTTC-3' and 5' ${ }^{\prime}$-ATG AATAATATAAATAAAATTTTTATAACATTTTTATGTATT GAACTGATATGGGAATTAGCCATGGTCC-3'. Cells were transformed by PCR product via electroporation and spread onto agar containing kanamycin. After overnight incubation at $37^{\circ} \mathrm{C}, \mathrm{Km}^{\mathrm{R}}$ colonies were recovered and maintained on antibiotic-free medium. Clones were tested for ampicillin sensitivity to confirm the loss of helper plasmid pKD20. The $w z y$ gene disruption was verified in clones by genomic sequencing using primers $5^{\prime}$-AACTATTTAGCTAATGTGCA-3' and $5^{\prime}$ CATAAATAATAAAAATGCTG- $3^{\prime}$. In the $\Delta w z y$ mutant, the $\mathrm{Km}^{\mathrm{R}}$ cassette from $\mathrm{pKD} 4$ replaced the $w z y$ gene from nucleotide 51 (downstream of translation initiation) to 1098.

\section{Preparation of Bacteria}

S. flexneri serotype 2a strain 2457T (Wei et al., 2003), serotype 3a, serotype 6, S. sonnei strain 482-79 (Sansonetti et al., 1980), strain $53 \mathrm{G}$ (Holt et al., 2012), and S. flexneri 2a live-attenuated vaccine strain SC602 (Coster et al., 1999) were used in this study. Bacteria including the $\Delta w z y$ mutant were subcultured from the frozen aliquots overnight at $37^{\circ} \mathrm{C}$ on Bacto ${ }^{\mathrm{TM}}$ Tryptic Soy (BTS) agar (BD, Sparks, MD) with $0.01 \%$ Congo red (SERVA, Heidelberg, Germany). One representative Congo red-stained colony was 
grown in BTS broth overnight at $37^{\circ} \mathrm{C}$ with continuous shaking. An aliquot of the $\Delta w z y$ overnight culture was added as $1 / 100$ $(\mathrm{v} / \mathrm{v})$ to fresh BTS broth and cultured for $2-3 \mathrm{~h}$ at $37^{\circ} \mathrm{C}$. After reaching an OD of 0.5 at $600 \mathrm{~nm}$ (corresponding to $2 \times 10^{8}$ $\mathrm{cfu} / \mathrm{ml}$ ), cells were recovered by centrifugation and suspended in phosphate-buffered saline (PBS; GIBCO, Waltham, MA). Bacteria were inactivated by treatment with $0.13 \%$ formalin (Sigma, Steinheim, Germany) in PBS $\left(2 \times 10^{8} \mathrm{cfu} / \mathrm{ml}\right)$ on a shaker for $2 \mathrm{~h}$ at a controlled room temperature of $22-23^{\circ} \mathrm{C}(\mathrm{RT})$. They were washed twice with PBS and stored at $4^{\circ} \mathrm{C}$ until mouse immunization on the same day. Inactivation of bacteria was confirmed by no colonies after overnight culture of inactivated bacteria $\left(2.5 \times 10^{8} \mathrm{cfu}\right)$ on BTS agar plates at $37^{\circ} \mathrm{C}$.

\section{LPS and IcsP Detection}

LPS was recovered from $\Delta w z y$ and wild type (WT) Shigella extracts using the phenol-water method (Marolda et al., 2006). Briefly, bacteria were cultured in BTS as described above; then, the bacteria $\left(2 \times 10^{9} \mathrm{cfu}\right)$ were suspended in $150 \mu \mathrm{l}$ PBS and lysed using lysis buffer containing DNase I (Roche, Mannheim, Germany) and proteinase K (Promega, Madison, USA). Samples were extracted by $90 \%$ phenol solution; then, the aqueous phase was recovered and extracted again by ethyl ether saturated with Tris-EDTA solution. LPS was obtained after centrifuging and discarding the ether phase. LPS was analyzed by $14 \%$ Tris/Tricine PAGE and silver staining. LPS silver staining was performed using Bio-Rad Silver Stain kit (BIO$\mathrm{RAD}$, Hercules, CA) according to manufacturer's instructions. Expression of outer membrane protein IcsP from $S$. flexneri $2 \mathrm{a}$ $2457 \mathrm{~T}$ WT and $\Delta w z y$ mutant was assessed. Three serial four-fold dilutions starting from $1 \times 10^{8} \mathrm{cfu}$ of whole cells were prepared in PBS. SDS-PAGE sample buffer (BIO-RAD) containing 2mercaptoethanol was added to the samples followed by boiling for $5 \mathrm{~min}$.

\section{Flow Cytometry}

The same amounts of Shigella WT and $\Delta$ wzy mutant cells $(1 \times$ $10^{7} \mathrm{cfu}$ ) were used for washing in PBS and incubation in dilutions of PSSP-1 specific polyclonal mouse sera at $4^{\circ} \mathrm{C}$ for $1 \mathrm{~h}$. After washing 3 times in PBS, goat anti-mouse IgG-RPE (Southern Biotech, Birmingham, AL) was added. After washing in PBS, cells were analyzed by a flow cytometry instrument (FACSCalibur BD Bioscience, San Jose, CA). Anti-serum against PSSP-1 (Kim et al., 2015) was generated after immunizing mice with four doses of PSSP-1 and co-administering Cholera Toxin (CT) at 2-week intervals via the intranasal route. Naïve mouse serum was used as control.

\section{Western Blot}

Cell lysates were resolved by $4-20 \%$ gradient SDS-PAGE (BIO RAD), transferred to PVDF membrane (BIO RAD), and incubated with mouse polyclonal anti-PSSP-1 (Fukuda et al., 1995) serum (1:500) for $1 \mathrm{~h} 30 \mathrm{~min}$ at RT in blocking buffer (PBS, 5\% skim milk, BD; 0.05\% Tween 20, Sigma) followed by washing. The blot was further incubated in blocking buffer with horseradish peroxidase (HRP)-conjugated goat anti-mouse IgG (1:5,000, Southern Biotech) for $1 \mathrm{~h}$ at RT and washed before detection with ECL reagent (ELPIS-Biotech, Daejeon, South Korea).

\section{In vitro Shigella Plaque Assay}

HeLa cells were seeded in 6-well plates (Nunc, St. Louis, MO) at a density of $4 \times 10^{5}$ cells per well and cultured for 1 day to reach full differentiation at $37^{\circ} \mathrm{C}$ with $5 \% \mathrm{CO}_{2}$, in RPMI-1640 (+25 mM HEPES, +L-Glutamine; HyClone, Logan, UT) containing 10\% heat-inactivated fetal bovine serum (FBS; GIBCO), penicillin $(100 \mathrm{U} / \mathrm{ml})$, and streptomycin $(100 \mu \mathrm{g} / \mathrm{ml}$; Oaks et al., 1985). In preparation of the plaque assay, monolayers were washed twice with PBS. Then, $0.5 \mathrm{ml}$ of diluted bacterial suspension $\left(10^{6}\right.$ and $10^{7} \mathrm{cfu}$ ) was added to the monolayer, which was subsequently incubated at $37^{\circ} \mathrm{C}$ for $90 \mathrm{~min}$ with plate-rocking every $30 \mathrm{~min}$ to assure uniform distribution of bacteria. To remove residual bacteria, the monolayer was incubated in RPMI-1640 containing $10 \% \mathrm{FBS}$ and $50 \mu \mathrm{g} / \mathrm{ml}$ gentamycin for $60 \mathrm{~min}$. Next, $0.5 \%$ agar was gently added to the wells. Cells were cultured for $48 \mathrm{~h}$. For enhanced visualization of the plaques, cells were stained with crystal violet (Sigma).

\section{Virulence Test of Shigella in Guinea Pigs}

Three-week-old female guinea pigs were used for comparison of the virulence of the Shigella wild type and wzy mutant strain ( $n=4$ per group). The guinea pigs were anesthetized before infection (intraperitoneal route: ketamine hydrochloride; Yuhan Co., Ltd., Seoul, South Korea, and xylazine hydrochloride, Bayer Korea, Seoul, South Korea). S. flexneri 2a 2457T WT $\left(5 \times 10^{3} \mathrm{cfu} / 20 \mu \mathrm{l}\right.$ of PBS $)$ and $\Delta w z y\left(5 \times 10^{8} \mathrm{cfu} / 20\right.$ $\mu \mathrm{l}$ of PBS) were intra-ocularly inoculated to the guinea pigs, and the severity of eye inflammation was monitored for 3 days as described in previous report (Sandlin et al., 1996).

\section{Immunization and Challenge of Mice}

Female Balb/c mice, 6 weeks old, received bacteria (S. flexneri $2 \mathrm{a}$ $\Delta w z y$ mutant, $1 \times 10^{8}$ or $1 \times 10^{7} \mathrm{cfu}$; SC602, $\left.5 \times 10^{6} \mathrm{cfu}\right)$ in $40 \mu \mathrm{l}$ of PBS by the intranasal route, 3 times at 2 -week intervals, under anesthesia (intraperitoneal route: ketamine hydrochloride and xylazine hydrochloride). Formalin-inactivated (F.I.) S. flexneri $2 \mathrm{a}$ WT $\left(1 \times 10^{8} \mathrm{cfu}\right.$ or $\left.1 \times 10^{7} \mathrm{cfu}\right)$, SC602 $\left(5 \times 10^{6} \mathrm{cfu}\right)$, and $\mathrm{dmLT}$ $(5 \mu \mathrm{g})$ adjuvant group were used as control. We immunized mice with SC602 $5 \times 10^{6} \mathrm{cfu}$ per mouse because they died at higher doses (Barzu et al., 1996). On day 7 after the last immunization, mice were intranasally challenged with live wild type $S$. flexneri 2a $2457 \mathrm{~T}\left(1 \times 10^{7} \mathrm{cfu}\right), S$. flexneri $3 \mathrm{a}\left(1 \times 10^{7} \mathrm{cfu}\right)$, S. flexneri $6\left(5 \times 10^{6} \mathrm{cfu}\right)$, S. sonnei $482-79\left(5 \times 10^{6} \mathrm{cfu}\right)$, and S. sonnei $53 \mathrm{G}\left(1 \times 10^{7} \mathrm{cfu}\right)$. Survival of mice was monitored daily for 14 days.

\section{Sera and Bronchoalveolar Lavage (BAL) Fluids}

Seven days after the third immunization, mice were anesthetized as described above to perform blood collection from orbital sinus. Whole blood was centrifuged at $600 \mathrm{~g}$ for $20 \mathrm{~min}$ to obtain serum. After bleeding, mice were sacrificed and BAL fluid was collected 
in $700 \mu \mathrm{l}$ of PBS. Sera and BAL fluids were stored at $-70^{\circ} \mathrm{C}$ until use.

\section{Enzyme-Linked Immunosorbent Assay (ELISA)}

Shigella-specific protein, IpaB, IpaC (Venkatesan et al., 1988), and IcsP (Fukuda et al., 1995), and Shigella whole cell-specific antibody levels in blood serum and BAL fluid were measured by ELISA as described previously (Shere et al., 1997; Kim et al., 2015). Briefly, 96 well-plates (Nunc., Rockilde, Denmark), were coated with $200 \mathrm{ng} /$ well of IpaB, IpaC, PSSP-1, LPS (S. flexneri 2a) in $100 \mu \mathrm{l}$ of PBS, at $4^{\circ} \mathrm{C}$ overnight. For whole-cell coating, $100 \mu \mathrm{l}$ of $5 \times 10^{5}$ cells/well of F.I.-Shigella whole cells in PBS were incubated for $4 \mathrm{~h}$ at RT followed by overnight at $4{ }^{\circ} \mathrm{C}$. After blocking with blocking buffer (1\% BSA in PBS), serial dilutions of sera or BAL fluids in blocking buffer were incubated for $2 \mathrm{~h}$ at RT. Then, HRP conjugated goat anti-mouse IgG $(1: 5,000$, Southern Biotech) were incubated for $1 \mathrm{~h}$ at RT. After final washing, peroxidase substrate (TMB; Moss, Pasadena, MD) was added per well for $10-15 \mathrm{~min}$ and $0.5 \mathrm{~N} \mathrm{HCl}$ was added for stopping the reaction. The OD was measured in an ELISA reader (Molecular Devices, Sunnyvale, CA). The antibody titer was expressed as the reciprocal $\log 2$ titer of dilution showing 0.2 of absorbance at $450 \mathrm{~nm}$.

\section{Enzyme-Linked Immunosorbent Spot Assay (ELISPOT)}

On day 7 after the third immunization, spleens were collected from the immunized mice. Single-cell suspensions were prepared as described previously (Kim et al., 2015). We coated 96well nitrocellulose microplates (Millipore, Bedford, MA) with purified recombinant PSSP-1 $(30 \mu \mathrm{g} / \mathrm{ml})$ in PBS and performed ELISPOT assay as described previously (Kim et al., 2015). PSSP1 -specific IgG or IgA spots were developed with $B C I P{ }^{\circledR} / N B T$ liquid substrate (Sigma) and counted by ImmunoSpot analyzer (Cellular Technology, Cleveland, OH).

\section{Statistical Analysis}

All the experiments were repeated at least two times and at least five mice were analyzed from each group. All analyses were performed using Prism 5 (GraphPad, San Diego, CA). Differences between individual groups were evaluated using the unpaired Student's $t$-test. A log rank (Mantel-Cox) test was used for comparing survival rates after challenge. Two-tailed $p$ values of $<0.05$ were considered statistically significant.

\section{RESULTS}

\section{Characteristics of the S. Flexneri 2a Mutant Strain $\Delta w z y$}

To develop a cross-protective vaccine against different Shigella species and serotypes, we constructed a Shigella mutant strain $\Delta w z y$, in which Oag polymerase gene $w z y$ is disrupted.

Purified LPS from $\Delta w z y$ and WT (S. flexneri 2a 2457T) was compared by SDS-PAGE and silver staining (Figure 1A). While LPS of WT showed a ladder pattern, LPS of $\Delta w z y$ showed only a rough pattern, which was consistent with a previous report (one Oag unit; Carter et al., 2009). To examine whether the Oag chain length affects the exposure level of surface proteins, $\Delta w z y$ and WT were incubated with PSSP-1-specific polyclonal serum (Kim et al., 2015) and subjected to flow cytometry (Figure 1B). We observed that PSSP-1-specific-antibodies did not bind to the bacterial surface of WT S. flexneri 2a 2457T, whereas the same anti-serum could bind to $\Delta w z y$. In western blot, IcsP protein expression levels were similar between $\Delta w z y$ and WT (Figure 1C). These data suggested that $\Delta w z y$ strain enhanced the exposure of surface proteins by shortening the Oag chain length.

\section{$\Delta w z y$ Mutant has an Attenuated Effect in vitro and in vivo}

To investigate the impact of shortened LPS-Oag chain on the virulence of $S$. flexneri 2a, we compared the infectivity of $\Delta w z y$ and WT strains in HeLa cells. WT cells formed plaques
A

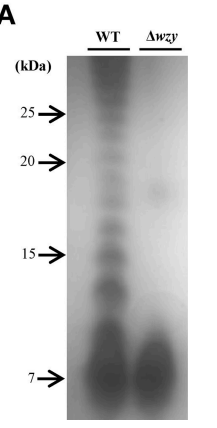

B
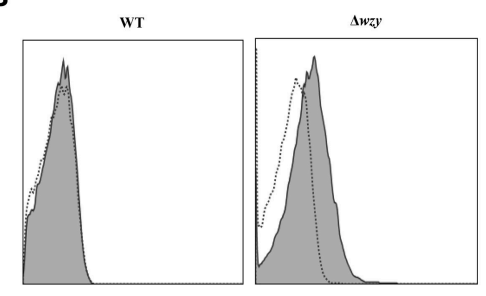

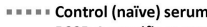

- PSSP-1-specific serum
C

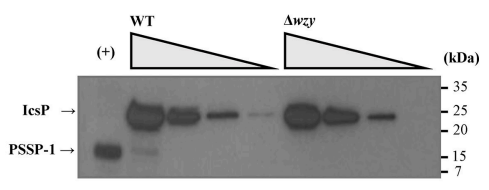

FIGURE 1 | Construction of S. flexneri 2a $\Delta$ wzy strain. (A) Analysis of LPS-Oag chain from wild type (WT) S. flexneri 2a 2457T and $\Delta$ wzy strains. Purified LPS from WT and $\Delta$ wzy strain were analyzed by $16.5 \%$ Tris/Tricine SDS PAGE (100 ng/lane) and silver staining. The laddering pattern, characteristic of Oag chains, was observed in the lane of WT but it disappeared in $\Delta$ wzy. (B) Exposure of outer membrane protein (IcsP) on the surface of $\Delta$ wzy strain. The whole cells (1 $\times 10^{7}$ cfu) were incubated with IcsP-specific mouse sera followed by secondary antibody conjugated with R-phycoerythrin. The cells were analyzed by flow cytometry. Control (naïve) sera (white histogram) and antigen-specific sera (gray histogram). (C) Comparison of lcsP expression between WT and $\Delta$ wzy strain. From left to right, $1 \times 10^{8}, 2.5 \times 10^{7}, 6.25$ $\times 10^{6}$, and $1.56 \times 10^{6}$ cfu of bacteria in PBS per lane was used for SDS-PAGE. Anti-PSSP-1 polyclonal serum was used for western blotting. Recombinant PSSP-1 (a C-terminal half-polypeptide of IcsP; $10 \mathrm{ng}$ ) was used for the positive control (+). Data are representative of at least two independent experiments. 
on HeLa cell monolayers, whereas $\Delta w z y$ did not (Figure 2A), indicating that the loss of virulence of $\Delta w z y$ strain with only one unit of Oag is consistent with the previous study (Morona et al., 2003).

We next examined the attenuated effect of $\Delta w z y$ strain in vivo. When the mice intranasally received $\Delta w z y$ strain $\left(1 \times 10^{9}\right.$ $\mathrm{cfu} /$ mouse), no mice died, in contrast to WT strain where all the mice died within 2 days following challenge with 10 times less

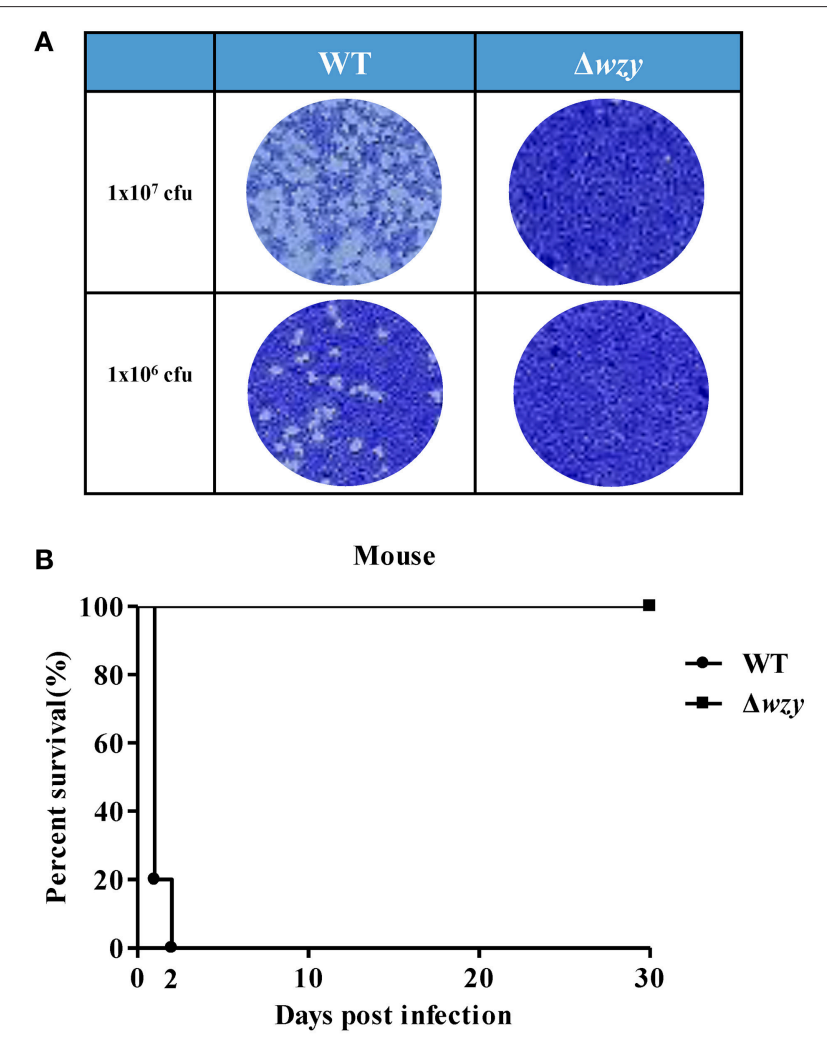

C

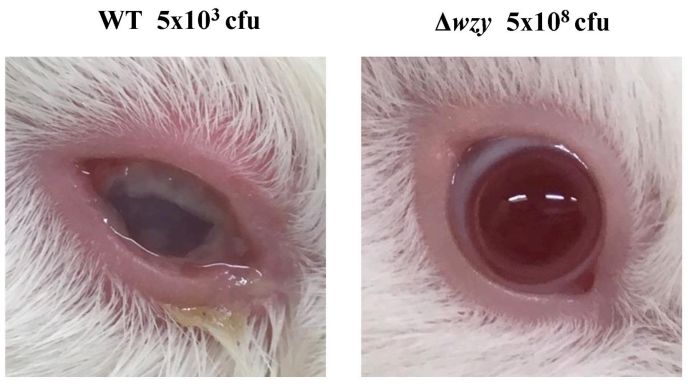

FIGURE 2 | Avirulent $\Delta W z y$ strain in vitro and in vivo. (A) WT and $\Delta W z y$ strain were cultured on HeLa cell monolayers for in vitro plaque assay. The bacteria $\left(1 \times 10^{7}\right.$ or $\left.1 \times 10^{6} \mathrm{cfu}\right)$ were infected into HeLa cells. After $48 \mathrm{~h}$, cells were stained with crystal violet. Data are representative of three independent experiments. (B) Virulence test of the $\Delta w z y$ strain in mice. Mice were intranasally administered with wild type (WT) S. flexneri 2a $2457 \mathrm{~T}$ and $\Delta w z y$ strain $\left(1 \times 10^{9} \mathrm{cfu}\right)$ and survival of the animals was monitored daily. $N=5$ for WT group and $N=10$ for $\Delta w z y$ group. (C) Virulence test of $\Delta w z y$ strain in guinea pig. Guinea pigs were ocularly inoculated with S. flexneri 2a 2457T WT $\left(5 \times 10^{3} \mathrm{cfu}\right)$ and $\Delta$ wzy $\left(5 \times 10^{8} \mathrm{cfu}\right)$. Data are representative of three independent experiments and the picture was taken on the third day after infection. amount of organisms $\left(1 \times 10^{8} \mathrm{cfu} /\right.$ mouse; Figure 2B $)$. Ocular inoculation of guinea pigs with $\Delta w z y$ strain $\left(5 \times 10^{8} \mathrm{cfu}\right)$ did not cause mucopurulent conjunctivitis in contrast to WT strain $\left(5 \times 10^{3} \mathrm{cfu}\right.$; Figure $\left.2 \mathrm{C}\right)$.

\section{$\Delta w z y$ Immunization in Mice Elevated Systemic and Local Humoral Immune Response}

To examine whether $\Delta w z y$ immunization effectively induces humoral immunity in mice, Balb/c mice intranasally received live $\Delta w z y$, F.I. $\Delta w z y$, F.I. $\Delta w z y$ plus dmLT (as adjuvant), or F.I. WT (positive control) 3 times at 2-week intervals.

We measured the serum IgG levels of IcsP, IpaB, IpaC, LPS (S. flexneri 2a), and F.I. WT S. flexneri 2a by ELISA. The mean values of anti-IpaB, IpaC or IcsP-specific serum IgG titers from all $\Delta w z y$ immunization groups were higher than from F.I. WT immunization groups (Figure 3A), suggesting that $\Delta w z y$ immunization enhanced protein antigen-specific humoral response. Additionally, anti-S. flexneri 2 a whole cell-specific IgG titers increased in all the $\Delta w z y$ immunized groups compared with that in the F.I. WT immunized group. Of note, the titer of F.I. $\Delta w z y$ plus dmLT immunized group was the highest among the $\Delta w z y$ immunized groups. The same tendency was not observed using LPS-coated ELISA plates. Although LPS-specific IgG titers were comparable among all immunized groups, that of F.I. $\Delta w z y$ plus dmLT immunized group was lower than the values for F.I. WT immunized group with statistical significance $(p<0.05)$. These results suggested that $\Delta w z y$ immunization elicited a stronger systemic humoral immune response to protein antigens than F.I. WT immunization, but not to LPS (Figure 3A). The antibody responses were highest when $\Delta w z y$ was combined with dmLT, except against LPS.

Next, we examined local antibody responses against Shigella proteins. BAL fluids were collected on the seventh day after the third immunization for measuring antibody titers. The results were similar to the systemic humoral response (Figure 3B). The IcsP-specific IgG level of the BAL fluid was increased to a greater degree in the group immunized with F.I. $\Delta w z y$ than in that immunized with F.I. WT $(p<0.05)$. Moreover, the IcsP, IpaB-, and IpaC-specific IgG levels in the BAL fluid from F.I. $\Delta w z y$ plus dmLT mice were all higher than those in F.I. WT samples $(p<0.01)$. Thus, $\Delta w z y$ with dmLT adjuvant induces both systemic and local antibody immune response to conserved Shigella proteins in mice.

To investigate whether elevated titers of antibody are associated with increased numbers of antibody-secreting B cells, we conducted ELISPOT assays using spleen from immunized mice, collected on day 7 after the third immunization, to enumerate PSSP-1-specific antibody-secreting cells. Live $\Delta w z y$ and F.I. $\Delta w z y$ plus dmLT immunized groups showed a statistically significant increase in IgG-secreting cell population ( $p<0.001$ and $p<0.01$, respectively), and F.I. $\Delta w z y$ plus dmLT immunized group showed a statistically significant increase in IgA-secreting cell population compared to F.I. WT immunized group ( $p<0.05$; Figure 4 ). The F.I $\Delta w z y$ plus dmLT group showed the highest number of both IgG- and IgA-secreting cells. 

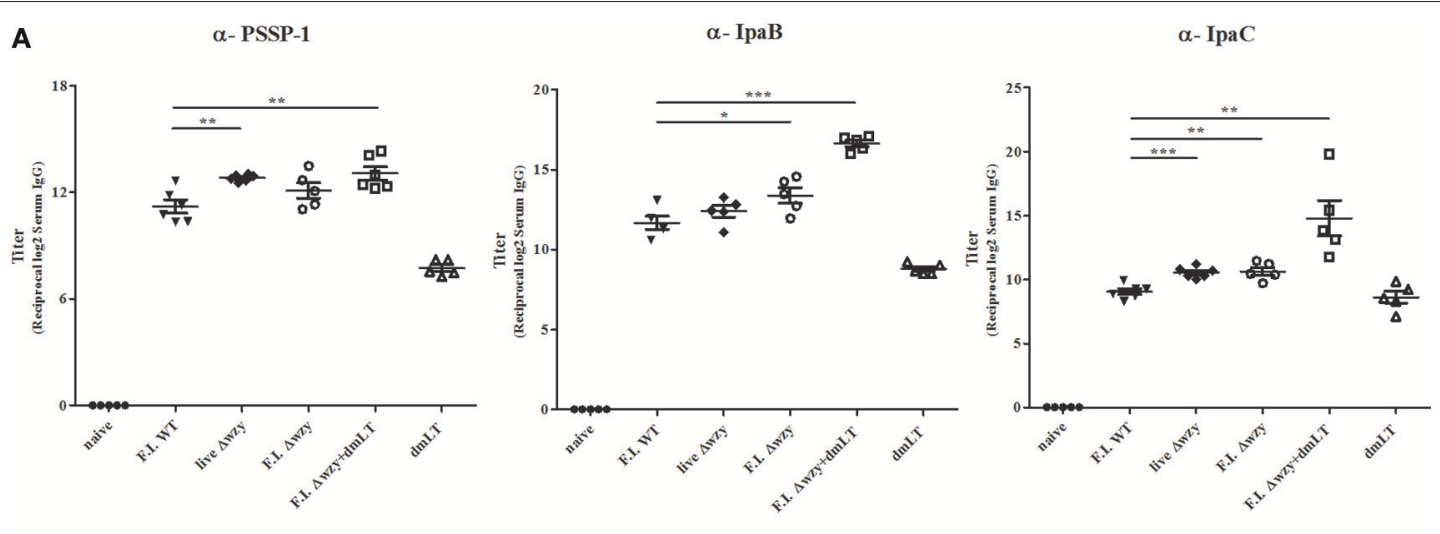

$\alpha$-F.I. S. flexneri 2a WT

$\alpha$-LPS (S. flexneri 2a WT)
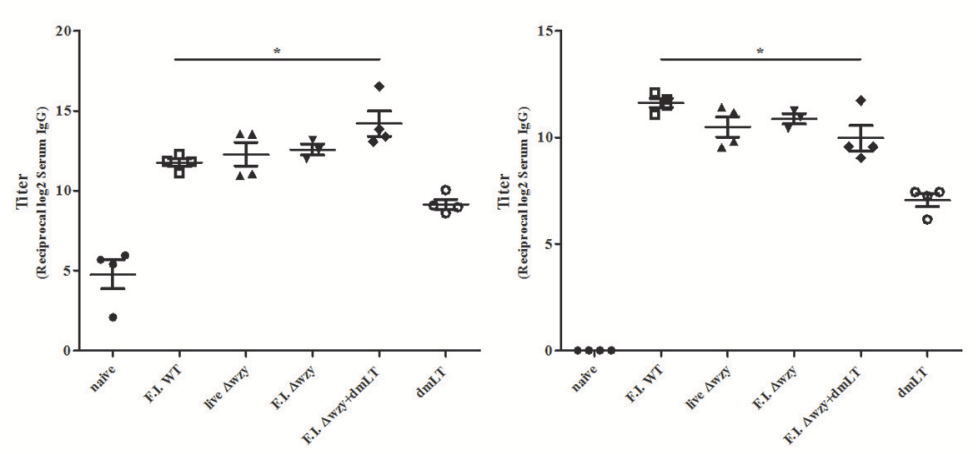

B

$\alpha$ - PSSP-1

$\alpha$ - IpaB

$\alpha$-IpaC
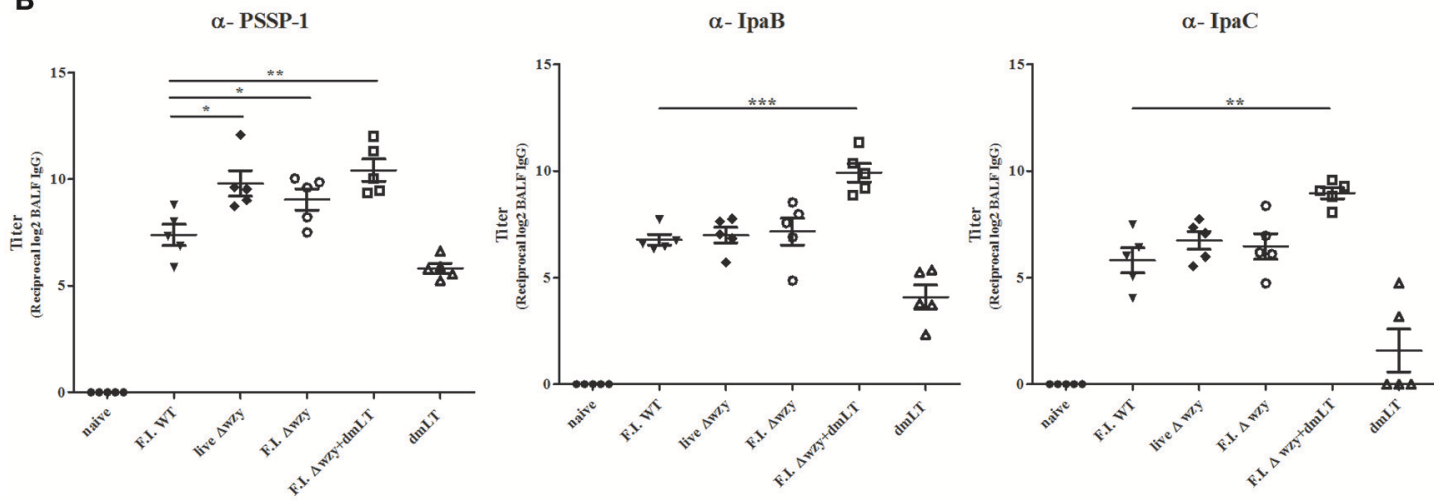

FIGURE 3 | Systemic and local antibody responses. Mice were immunized intranasally 3 times at 2 week-intervals with F.I. WT, live $\Delta$ wzy, F.I. $\Delta$ wzy, and F.I. $\Delta$ wzy plus $\mathrm{dmLT}$, and $\mathrm{dmLT}$ alone. On the 7th day after the 3rd immunization, serum and BAL fluid (BALF) were collected from individual mouse. IgG level were determined by ELISA. (A) Measurement of PSSP-1-, IpaB-, IpaC-, LPS (S. flexneri 2a)-, and F.I. S. flexneri 2a-specific IgG: $N=4-5$ per each group. (B) Measurement of PSSP-1-, IpaB-, and IpaC-specific IgG in BALF samples: $N=5$ per each group. Data are means \pm SEM and representative of two independent experiments. ${ }^{*} p<0.05,{ }^{* *} p<0.01$, and ${ }^{* * *} p<0.001$.

\section{$\Delta w z y$ Strain Is Cross-Serotype Protection Against Shigella Challenges in the Mouse Pneumonia Model}

We screened for evidence of protective efficacy conferred by $\Delta w z y$ immunization against several species and serotypes of Shigella by using a mouse pneumonia model (Voino-Yasenetsky and Voino-Yasenetskaya, 1961). Using an immunization dose of $1 \times 10^{7}$ cfu per mouse, the F.I. $\Delta w z y$ plus dmLT immunized group provided $100 \%$ protective efficacy equivalent to that provided by SC602 $\left(5 \times 10^{6} \mathrm{cfu} /\right.$ mouse $)$ but higher than that of F.I. WT $\left(1 \times 10^{7} \mathrm{cfu} /\right.$ mouse $)$ against challenge with $S$. flexneri 2a (Figure 5A). However, there was no statistically significant 

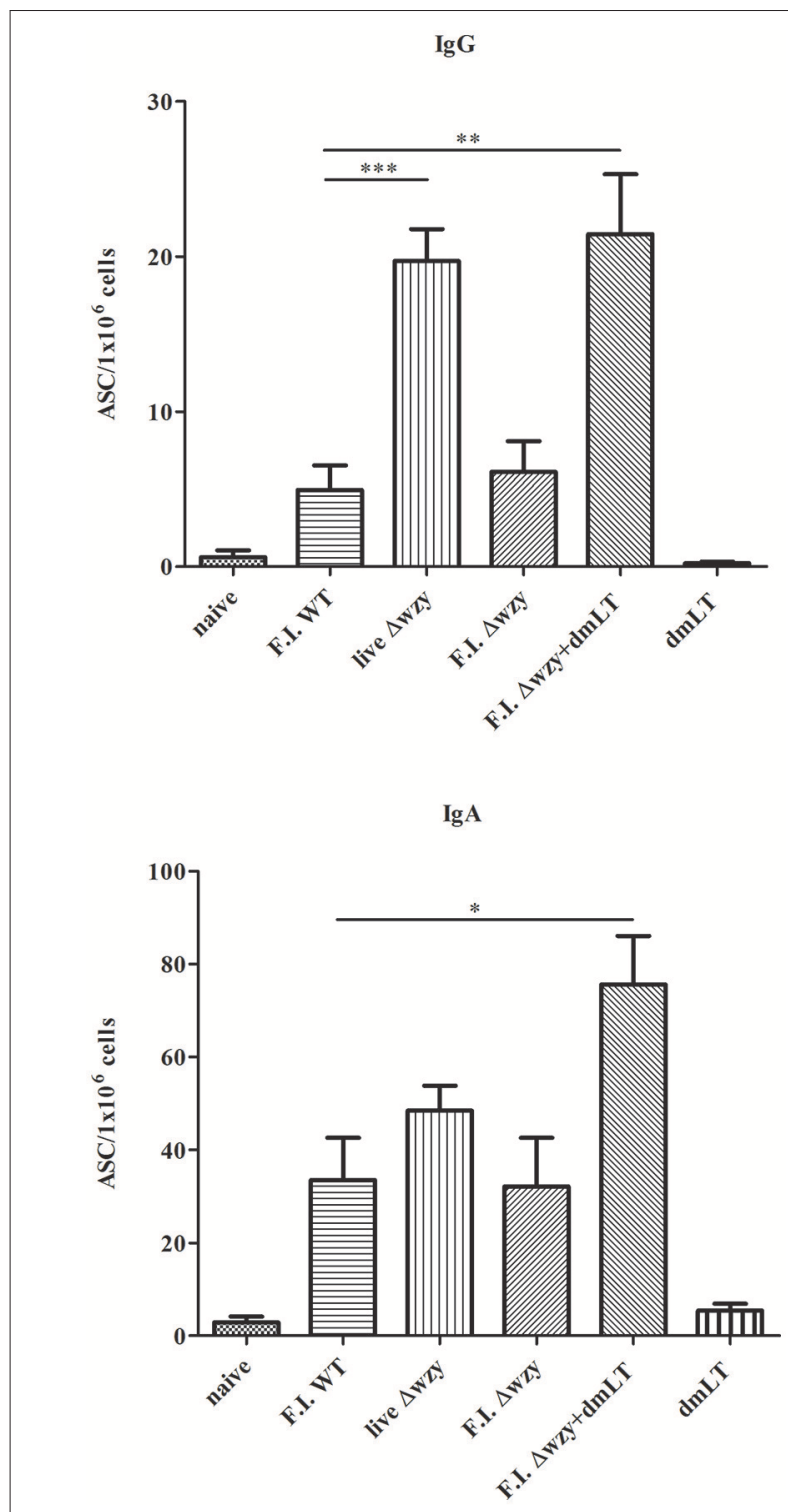

FIGURE 4 | Increased numbers of PSSP-1 specific IgG- or IgA-secreting cells from the mice immunized with F.I. $\Delta$ wzy plus dmLT. Single cell suspensions from spleen were prepared on the 7th day after the 3rd immunization with F.I. WT, live $\Delta w z y$, F.I. $\Delta w z y$, and F.I. $\Delta w z y$ plus $d m L T$, and dmLT alone. Anti-PSSP-1-specific lgG- (upper panel) or IgA- (lower panel) secreting B cells were detected with ELISPOT assay. The numbers of antibody-secreting cells (ASC) per $1 \times 10^{6}$ cells are shown. $N=3$ per each group. Data are means \pm SEM and are representative of two independent experiments. ${ }^{\star} p<0.05$, ${ }^{* *} p<0.01$, and ${ }^{* * *} p<0.001$.

difference between groups except in comparison to the group treated with dmLT alone $(p<0.05)$. Using an immunization dose of $1 \times 10^{8} \mathrm{cfu}$ per mouse, all immunized groups except the negative control (naïve or dmLT alone) groups provided complete protection against $S$. flexneri 2a 2457T $(p<0.05)$. Similarly, the F.I $\Delta w z y$ plus dmLT immunized groups had the highest protection against $S$. flexneri 3a, S. flexneri 6, and against both $S$. sonnei $482-79$ and 53G strains. In contrast, the protective efficacy of F.I. WT and SC602 immunized groups were low ( $\leq 20 \%$ except F.I. WT against S.flexneri 3a challenge; Figure 5B). While $S$. flexneri 2a vaccine strain SC602 showed strong protective efficacy against only $S$. flexneri $2 \mathrm{a}$, the $\Delta w z y$ strain showed protective efficacy against $S$. flexneri $(2 \mathrm{a} / 3 \mathrm{a} / 6)$ and S. sonnei strains (482-79/53G). The control group treated with dmLT alone showed a survival rate of $20 \%$ against $S$. sonnei 482-79 and no protection against any other Shigella strain. These data indicated that dmLT did not induce non-specific protection but played a role as adjuvant. Thus, dmLT adjuvanted S. flexneri 2a $\Delta w z y$ induces serotype-independent protection against experimental shigellosis.

\section{Discussion}

We found evidence to support the further development of a new paradigm for immunization against Shigella through use of conserved serotype-independent antigens. Protection against infection with Shigella can be attributed to the serotype specific immunity induced by the O-polysaccharide component of the bacterial LPS (Morona et al., 2003; Camacho et al., 2013). Our data suggest that this component can mask serotype-independent protein antigens on the cell surface so that the immune response to them is not as effective as that directed against the Oag. We demonstrated this through construction of the $\Delta w z y$ mutant of Shigella that left the surface protein antigens unmasked. In this situation, higher titers to surface proteins were seen in mice immunized with the mutant compared to wild type Shigella. Although many proteins are found on the cell surface, we tested for the several that have been associated previously with protection of mice against a variety of serotypes: Ipa B (Heine et al., 2014) and PSSP-1 (Kim et al., 2015). The titers to these antigens were higher in mice immunized with the mutant than those that received the WT cells.

The construction of a mutant with better responses to conserved proteins than normally seen suggested that the mutant would have a broad coverage over the key clinical serotypes of Shigella. Instead of 4 serotypes to cover S. flexneri 2a, 3a, and 6 , and S. sonnei, it may be possible to achieve cross-serotype protection with $\Delta w z y$ mutants from one serotype. We tested this hypothesis and found that the S. flexneri 2a $\Delta w z y$ vaccine, when administered intranasally, enhanced systemic and mucosal immunity to conserved outer membrane proteins such as PSSP-1, IpaB, and IpaC. Moreover, the Shigella $\Delta w z y$ vaccine construct, when co-administered with the mucosal adjuvant dmLT, evoked stronger serogroup- and serotype-independent protection than the vaccine strain given without the adjuvant.

Given the structural variability and poor antigenic crossreactivity of Oag-based polysaccharides among the multiple Shigella serotypes, a cocktail or combination of Oags from the most relevant species and serotypes would be required for an effective vaccine (Kotloff et al., 2013). Moreover, polysaccharides induce a $\mathrm{T}$ cell-independent antibody response and poor memory B cell responses (Mosier and Subbarao, 1982), which limit the potential of Oag-based vaccines in young children and infants, who constitute the most vulnerable age groups for Shigella infection. Some preclinical studies have identified several cell wall-associated proteins, including Ipa proteins and PSSP-1, 

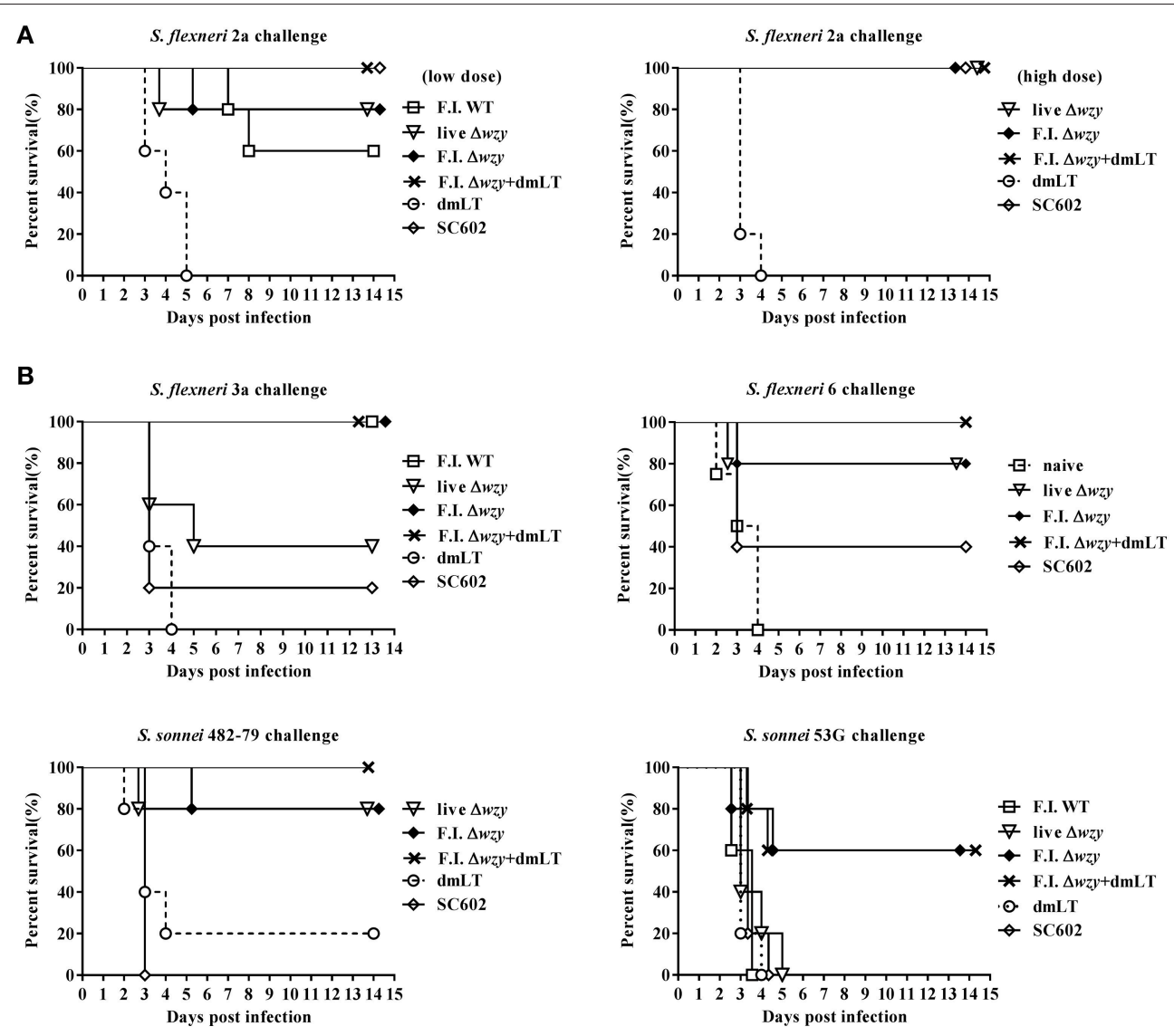

FIGURE 5 | S. flexneri 2a $\Delta$ wzy strain provides cross-protection against Shigella challenges in mouse pneumonia model. Mice were intranasally immunized with F.I. WT, live $\Delta w z y$, F.l. $\Delta w z y$, F.I. $\Delta$ wzy plus dmLT $(5 \mu \mathrm{g})$, dmLT alone or SC602 (S. flexneri 2a vaccine strain; $5 \times 10^{6} \mathrm{cfu}$ ) 3 times at 2-week intervals. On the 7 th day after the 3rd immunization, mice were intranasally challenged with virulent $S$. flexneri 2a $2457 \mathrm{~T}\left(1 \times 10^{7} \mathrm{cfu} / \mathrm{mouse}\right), \mathrm{S}$. flexneri $3 \mathrm{a}\left(1 \times 10^{7} \mathrm{cfu} / \mathrm{mouse}\right), \mathrm{S}$. flexneri $6(5 \times$

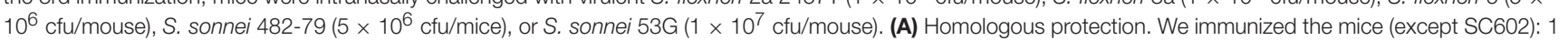
$\times 10^{7} \mathrm{cfu}$ per mouse (left graph) and $1 \times 10^{8} \mathrm{cfu}$ per mouse (right graph). (B) Heterologous protection. We immunized the mice (except SC602): $1 \times 10^{8} \mathrm{cfu}$ per mouse. Survival of animals was monitored daily. $N=5$ per each group. Data are representative of at least two independent experiments. Upper left panel: $p<0.01$, F.I. WT, F.I. $\Delta w z y$, and F.I. $\Delta$ wzy plus dmLT vs. dmLT; $p<0.05$, F.I. WT, F.I. $\Delta w z y$, and F.I. $\Delta$ wzy plus dmLT vs. SC602. Upper right panel: $p<0.01$, F.I $\Delta$ wzy plus dmLT vs. naïve; $p<0.05$, F.I $\Delta$ wzy plus dmLT vs. SC602, live $\Delta$ wzy and F.I $\Delta$ wzy vs. naïve. Lower left panel: $p<0.05$, F.I. $\Delta$ wzy plus dmLT vs. dmLT; $p<0.01$, F.I. $\Delta$ wzy plus dmLT vs. SC602; $p<0.05$, live $\Delta$ wzy and F.I. $\Delta$ wzy vs. SC602. Lower right panel: $p<0.05$, F.I. $\Delta w z y$ and F.I. $\Delta w z y$ plus dmLT vs. dmLT, and vs. SC602.

that are conserved among Shigella species and serotypes and thus may provide cross-protection among serotypes (MartinezBecerra et al., 2013; Walker, 2015). IpaB and IpaC are key virulence factors of $S$. flexneri, and are essential for host cell invasion and intracellular survival (Menard et al., 1993, 1994; Blocker et al., 1999). Owing to their high conservation and role in virulence, Ipa proteins are attractive target antigens in the formulation of a cross-protective shigellosis vaccine (Oaks et al., 1986). Of note, we previously identified PSSP-1, the Cterminal moiety of the IcsP outer membrane protein, as a major Shigella cross-protective antigen in murine shigellosis models (Kim et al., 2015). However, PSSP-1-specific antibodies bound poorly to Shigella whole cells, which is consistent with recent work indicating that IcsP is masked by LPS-Oag (Tran et al., 2013). Based on these observations, we constructed a Shigella strain expressing monomeric Oag so as to enhance exposure of IcsP and other surface proteins while partly retaining the $\mathrm{O}$ antigenicity. Determination of the glucosylation pattern of the
Oag unit of the $\Delta w z y$ strain may be needed to study the detailed structure and its effect on immunogenicity in the absence of the $w z y$ gene in future studies.

The live $\Delta w z y$ mutant behaved as an attenuated vaccine in mice and guinea pigs that were challenged with the mutant and was found not to form plaques in cell culture. The option of using live attenuated mutants with truncated O-polysaccharide side chains remains, but we focused on an inactivated whole cell formulation. Formalin-inactivated (F.I.) $\Delta w z y$ was used to minimize the risks of reactogenicity, particularly if the vaccine is used on an EPI schedule in children who may be most sensitive. Further, in case the mutant is combined with another cell type in a future vaccine strategy, formulation of inactivated cell combinations could be more readily accomplished than a combination of live cells. Inactivated cells also have the option of being used in liquid suspensions rather than lyophilized preparations. Inactivated WT Shigella has been shown to be safe and immunogenic in adult volunteers (McKenzie et al., 2006; 
Chakraborty et al., 2016) which argues for the usefulness of inactivated cells as oral vaccines. More recently, the inactivated whole cell ETEC vaccine, ETVAX, which includes dmLT, was safe and immunogenic in Swedish adults (Lundgren et al., 2014) and in Bangladeshi children as young as 6 months of age. The inclusion of $\mathrm{dmLT}$ in this latter group of children significantly enhanced their immune response (data in preparation). This adjuvant promotes Th17-driven responses that have been shown to support protective immune responses against $S$. flexneri infection (Brereton et al., 2011; Leach et al., 2012). Our data showed that dmLT did not induce non-specific protection, but played the role of an adjuvant in the present study.

Specifically, Shigella is an invasive enteropathogenic bacterium that is responsible for bacillary dysentery and causes inflammatory destruction of the human colonic mucosa. Mucosal antibody, especially secretory IgA, developed by $\Delta w z y$ vaccination would bind to Shigella surface antigens when they become transiently accessible to dividing bacteria and thereby prevent Shigella from penetrating the epithelial barrier. Mucosal IgA antibodies directed to Ipa proteins have been found in adults and well-nourished children but not in undernourished children convalescing from shigellosis (Oberhelman et al., 1991). We have also found that patients with recent onset shigellosis rarely mount gut mucosal antibody responses to IcsP. These observations suggest that a $\Delta w z y$ vaccine can potentially elevate antibody levels to Ipa proteins and IcsP, and thus facilitate protection against Shigella, particularly in high-risk pediatric age groups. Further data are needed to better establish the benefit of conserved protein antigens in protecting against Shigella.

In conclusion, our study indicates that the $\Delta w z y$ vaccine construct, when administered by a mucosal route, can induce strong systemic and mucosal immunity to several conserved cross-protective surface proteins. If promising results can be further substantiated, they should be followed by clinical

\section{REFERENCES}

Barry, E. M., Pasetti, M. F., Sztein, M. B., Fasano, A., Kotloff, K. L., and Levine, M. M. (2013). Progress and pitfalls in Shigella vaccine research. Nat. Rev. Gastroenterol. Hepatol. 10, 245-255. doi: 10.1038/nrgastro. 2013.12

Barzu, S., Fontaine, A., Sansonetti, P., and Phalipon, A. (1996). Induction of a local anti-IpaC antibody response in mice by use of a Shigella flexneri 2 a vaccine candidate: implications for use of IpaC as a protein carrier. Infect. Immun. 64, 1190-1196.

Blocker, A., Gounon, P., Larquet, E., Niebuhr, K., Cabiaux, V., Parsot, C., et al. (1999). The tripartite type III secreton of Shigella flexneri inserts IpaB and IpaC into host membranes. J. Cell Biol. 147, 683-693. doi: 10.1083/jcb.147. 3.683

Brereton, C. F., Sutton, C. E., Ross, P. J., Iwakura, Y., Pizza, M., Rappuoli, R., et al. (2011). Escherichia coli heat-labile enterotoxin promotes protective Th17 responses against infection by driving innate IL-1 and IL-23 production. J. Immunol. 186, 5896-5906. doi: 10.4049/jimmunol.1003789

Camacho, A. I., Irache, J. M., and Gamazo, C. (2013). Recent progress towards development of a Shigella vaccine. Expert Rev. Vaccines 12, 43-55. doi: $10.1586 /$ erv.12.135

Carter, J. A., Jimenez, J. C., Zaldivar, M., Alvarez, S. A., Marolda, C. L., Valvano, M. A., et al. (2009). The cellular level of O-antigen polymerase Wzy determines chain length regulation by WzzB and WzzpHS-2 in safety and efficacy studies to evaluate the performance and programmatic utility of this vaccine candidate for use in Shigella endemic regions. In the meantime, the stronger immune responses to PSSP-1 and to IpaB and IpaC seen in mice given the $\Delta w z y$ mutant than the WT would suggest that the $\Delta w z y$ mutant may also be an effective vector for heterologous antigens.

\section{AUTHOR CONTRIBUTIONS}

RW, CC, DK, and JK conceived and designed experiments. MK, $\mathrm{YM}, \mathrm{HK}$, and SR performed all experiments. MK, YM, and HK analyzed the data. MS, YS, DK, and JK provided the resource. MK, HK, and JK drafted the manuscript. RW, CC, DK, and JK reviewed the manuscript. All authors read and approved the final manuscript.

\section{FUNDING}

This work was supported by grants from PATH, Korea Health Industry Development Institute (KHIDI-HI13C0826), National Research Foundation of Korea (NRF-2017R1A1A3A04069676), and the governments of the Republic of Korea and Sweden (SIDA).

\section{ACKNOWLEDGMENTS}

We appreciate Prof. John D. Clements (Tulane University School of Medicine) for providing dmLT, and Dr. Robert W. Kaminski (Walter Reed Army Institute of Research) for providing purified Shigella LPS and IpaB protein. We thank Dr. Lou Bourgeois and Dr. Thomas Wierzba (PATH) for their great support and advice throughout this study. We also appreciate Dr. Ayan Dey and Ms. Sena Lee for their careful and critical reading of our manuscript.
Shigella flexneri 2a. Microbiology 155(Pt 10), 3260-3269. doi: 10.1099/mic.0. 028944-0

Chakraborty, S., Harro, C., DeNearing, B., Bream, J., Bauers, N., Dally, L., et al. (2016). Evaluation of the safety, tolerability, and immunogenicity of an oral, inactivated whole-cell Shigella flexneri 2a vaccine in healthy adult subjects. Clin. Vaccine Immunol. 23, 315-325. doi: 10.1128/CVI.00608-15

Coster, T. S., Hoge, C. W., VanDeVerg, L. L., Hartman, A. B., Oaks, E. V., Venkatesan, M. M., et al. (1999). Vaccination against shigellosis with attenuated Shigella flexneri 2a strain SC602. Infect. Immun. 67, 3437-3443.

Datsenko, K. A., and Wanner, B. L. (2000). One-step inactivation of chromosomal genes in Escherichia coli K-12 using PCR products. Proc. Natl. Acad. Sci. U.S.A. 97, 6640-6645. doi: 10.1073/pnas.120163297

Fukuda, I., Suzuki, T., Munakata, H., Hayashi, N., Katayama, E., Yoshikawa, M., et al. (1995). Cleavage of Shigella surface protein VirG occurs at a specific site, but the secretion is not essential for intracellular spreading. J. Bacteriol. 177, 1719-1726. doi: 10.1128/jb.177.7.1719-1726.1995

Guerrant, R. L., Oriá, R. B., Moore, S. R., Oriá, M. O., and Lima, A. A. (2008). Malnutrition as an enteric infectious disease with long-term effects on child development. Nutr. Rev. 66, 487-505. doi: 10.1111/j.1753-4887.2008. 00082.x

Heine, S. J., Diaz-McNair, J., Andar, A. U., Drachenberg, C. B., van de Verg, L., Walker, R., et al. (2014). Intradermal delivery of Shigella IpaB and IpaD type III secretion proteins: kinetics of cell recruitment and antigen uptake, mucosal 
and systemic immunity, and protection across serotypes. J. Immunol. 192, 1630-1640. doi: 10.4049/jimmunol.1302743

Holt, K. E., Baker, S., Weill, F.-X., Holmes, E. C., Kitchen, A., Yu, J., et al. (2012). Shigella sonnei genome sequencing and phylogenetic analysis indicate recent global dissemination from Europe. Nat. Genet. 44:1056. doi: 10.1038/ ng.2369

Hosangadi, D., Smith, P. G., Kaslow, D. C., Giersing, B. K., Who, E., and Shigella Vaccine Consultation Expert, G. (2018). "WHO consultation on ETEC and Shigella burden of disease," in Meeting Report Vaccine (Geneva).

Jann, K., Goldemann, G., Weisgerber, C., Wolf-Ullisch, C., and Kanegasaki, S. (1982). Biosynthesis of the O9 antigen of Escherichia coli. initial reaction and overall mechanism. Eur. J. Biochem. 127, 157-164. doi: 10.1111/j.1432-1033.1982.tb06850.x

Kim, J.-O., Rho, S., Kim, S. H., Kim, H., Song, H. J., Kim, E. J., et al. (2015). Shigella outer membrane protein PSSP-1 is broadly protective against Shigella infection. Clin. Vaccine Immunol. 22, 381-388. doi: 10.1128/CVI. 00661-14

Kotloff, K. L., Nataro, J. P., Blackwelder, W. C., Nasrin, D., Farag, T. H., Panchalingam, S., et al. (2013). Burden and aetiology of diarrhoeal disease in infants and young children in developing countries (the Global Enteric Multicenter Study, GEMS): a prospective, casecontrol study. Lancet 382, 209-222. doi: 10.1016/S0140-6736(13) 60844-2

Leach, S., Clements, J. D., Kaim, J., and Lundgren, A. (2012). The adjuvant double mutant Escherichia coli heat labile toxin enhances IL-17A production in human $\mathrm{T}$ cells specific for bacterial vaccine antigens. PLoS ONE 7:e51718. doi: 10.1371/journal.pone.0051718

Liu, J., Platts-Mills, J. A., Juma, J., Kabir, F., Nkeze, J., Okoi, C., et al. (2016). Use of quantitative molecular diagnostic methods to identify causes of diarrhoea in children: a reanalysis of the GEMS case-control study. Lancet 388, 1291-1301. doi: 10.1016/S0140-6736(16)31529-X

Lozano, R., Naghavi, M., Foreman, K., Lim, S., Shibuya, K., Aboyans, V., et al. (2012). Global and regional mortality from 235 causes of death for 20 age groups in 1990 and 2010: a systematic analysis for the Global Burden of Disease Study 2010. Lancet 380, 2095-2128. doi: 10.1016/S0140-6736(12) 61728-0

Lundgren, A., Bourgeois, L., Carlin, N, Clements, J., Gustafsson, B., Hartford, M., et al. (2014). Safety and immunogenicity of an improved oral inactivated multivalent enterotoxigenic Escherichia coli (ETEC) vaccine administered alone and together with dmLT adjuvant in a double-blind, randomized, placebo-controlled phase I study. Vaccine 32, 7077-7084. doi: 10.1016/j.vaccine.2014.10.069

Mani, S., Wierzba, T., and Walker, R. I. (2016). Status of vaccine research and development for Shigella. Vaccine 34, 2887-2894. doi: 10.1016/j.vaccine.2016.02.075

Marolda, C. L., Lahiry, P., Vinés, E., Saldías, S., and Valvano, M. A. (2006). Micromethods for the characterization of lipid A-core and O-antigen lipopolysaccharide. Methods Mol. Biol. 347, 237-252. doi: 10.1385/1-59745-167-3:237

Martinez-Becerra, F. J., Chen, X., Dickenson, N. E., Choudhari, S. P., Harrison, K., Clements, J. D., et al. (2013). Characterization of a novel fusion protein from $\mathrm{IpaB}$ and IpaD of Shigella spp. and its potential as a pan-Shigella vaccine. Infect. Immun. 81, 4470-4477. doi: 10.1128/IAI.00859-13

McKenzie, R., Walker, R. I., Nabors, G. S., Van De Verg, L. L., Carpenter, C., Gomes, G., et al. (2006). Safety and immunogenicity of an oral, inactivated, whole-cell vaccine for Shigella sonnei: preclinical studies and a Phase I trial. Vaccine 24, 3735-3745. doi: 10.1016/j.vaccine.2005.07.014

Menard, R., Sansonetti, P., and Parsot, C. (1994). The secretion of the Shigella flexneri Ipa invasins is activated by epithelial cells and controlled by IpaB and IpaD. EMBO J. 13, 5293-5302. doi: 10.1002/j.1460-2075.1994.tb06 863.x

Menard, R., Sansonetti, P. J., and Parsot, C. (1993). Nonpolar mutagenesis of the ipa genes defines IpaB, IpaC, and IpaD as effectors of Shigella flexneri entry into epithelial cells. J. Bacteriol. 175, 5899-5906. doi: 10.1128/jb.175.18.5899-59 06.1993

Morona, R., Daniels, C., and Van Den Bosch, L. (2003). Genetic modulation of Shigella flexneri 2a lipopolysaccharide $\mathrm{O}$ antigen modal chain length reveals that it has been optimized for virulence. Microbiology 149, 925-939. doi: 10.1099/mic.0.26141-0

Mosier, D. E., and Subbarao, B. (1982). Thymus-independent antigens: complexity of B-lymphocyte activation revealed. Immunol. Today 3, 217-222. doi: 10.1016/0167-5699(82)90095-0

Niehaus, M. D., Moore, S. R., Patrick, P. D., Derr, L. L., Lorntz, B., Lima, A. A., et al. (2002). Early childhood diarrhea is associated with diminished cognitive function 4 to 7 years later in children in a northeast Brazilian shantytown. Am. J. Trop. Med. Hyg. 66, 590-593. doi: 10.4269/ajtmh.2002. 66.590

Oaks, E. V., Hale, T., and Formal, S. (1986). Serum immune response to Shigella protein antigens in rhesus monkeys and humans infected with Shigella spp. Infect. Immun. 53, 57-63.

Oaks, E. V., Wingfield, M. E., and Formal, S. B. (1985). Plaque formation by virulent Shigella flexneri. Infect. Immun. 48, 124-129.

Oberhelman, R., Kopecko, D., Salazar-Lindo, E., Gotuzzo, E., Buysse, J., Venkatesan, M., et al. (1991). Prospective study of systemic and mucosal immune responses in dysenteric patients to specific Shigella invasion plasmid antigens and lipopolysaccharides. Infect. Immun. 59, 2341-2350.

Ouyang-Latimer, J., Jafri, S., VanTassel, A., Jiang, Z.-D., Gurleen, K., Rodriguez, S., et al. (2011). In vitro antimicrobial susceptibility of bacterial enteropathogens isolated from international travelers to Mexico, Guatemala, and India from 2006 to 2008. Antimicrob. Agents Chemother. 55, 874-878. doi: 10.1128/AAC.00739-10

Raetz, C. R., and Whitfield, C. (2002). Lipopolysaccharide endotoxins. Annu. Rev. Biochem. 71, 635-700. doi: 10.1146/annurev.biochem.71.110601. 135414

Ranallo, R. T., Barnoy, S., Thakkar, S., Urick, T., and Venkatesan, M. M. (2006). Developing live Shigella vaccines using $\lambda$ Red recombineering. FEMS Immunol. Med. Microbiol. 47, 462-469. doi: 10.1111/j.1574-695X.2006. 00118.x

Sandlin, R. C., Goldberg, M. B., and Maurelli, A. T. (1996). Effect of O side-chain length and composition on the virulence of Shigella flexneri 2a. Mol. Microbiol. 22, 63-73. doi: 10.1111/j.1365-2958.1996.tb02656.x

Sansonetti, P., David, M., and Toucas, M. (1980). Correlation between the loss of plasmid DNA and the transition from virulent phase I to avirulent phase II in Shigella sonnei. C. R. Seances. Acad. Sci. D 290, 879-882.

Shere, K. D., Sallustio, S., Manessis, A., D’Aversa, T. G., and Goldberg, M. B. (1997). Disruption of IcsP, the major Shigella protease that cleaves IcsA, accelerates actin-based motility. Mol. Microbiol. 25, 451-462.

Tran, E. N. H., Doyle, M. T., and Morona, R. (2013). LPS unmasking of Shigella flexneri reveals preferential localisation of tagged outer membrane protease IcsP to septa and new poles. PLOS ONE 8:e70508. doi: 10.1371/journal.pone.0070508

Tribble, D. R. (2017). Resistant pathogens as causes of traveller's diarrhea globally and impact (s) on treatment failure and recommendations. J. Travel Med. 24(Suppl. 1), S6-S12. doi: 10.1093/jtm/taw090

Valvano, M. A. (2003). Export of O-specific lipopolysaccharide. Front. Biosci. 8:S452-S471. doi: 10.2741/1079

van der Ley, P., Kuipers, O., Tommassen, J., and Lugtenberg, B. (1986). O-antigenic chains of lipopolysaccharide prevent binding of antibody molecules to an outer membrane pore protein in Enterobacteriaceae. Microb. Pathog. 1, 43-49. doi: 10.1016/0882-4010(86) 90030-6

Venkatesan, M. M., Buysse, J. M., and Kopecko, D. J. (1988). Characterization of invasion plasmid antigen genes (ipaBCD) from Shigella flexneri. Proc. Natl. Acad. Sci. U.S.A. 85, 9317-9321. doi: 10.1073/pnas.85. 23.9317

Voino-Yasenetsky, M., and Voino-Yasenetskaya, M. (1961). Experimental pneumonia caused by bacteria of the Shigella group. Acta Morphol. Acad. Sci. Hung. 11, 439-454.

Von Seidlein, L., Kim, D. R., Ali, M., Lee, H., Wang, X., Thiem, V. D., et al. (2006). A multicentre study of Shigella diarrhoea in six Asian countries: disease burden, clinical manifestations, and microbiology. PLoS Med. 3:e353. doi: 10.1371/journal.pmed.0030353 
Walker, R. I. (2015). An assessment of enterotoxigenic Escherichia coli and Shigella vaccine candidates for infants and children. Vaccine 33, 954-965. doi: 10.1016/j.vaccine.2014.11.049

Wei, J., Goldberg, M., Burland, V., Venkatesan, M., Deng, W., Fournier, G., et al. (2003). Complete genome sequence and comparative genomics of Shigella flexneri serotype 2a strain 2457T. Infect. Immun. 71, 2775-2786. doi: 10.1128/IAI.71.5.2775-2786.2003

West, N. P., Sansonetti, P., Mounier, J., Exley, R. M., Parsot, C., Guadagnini, S., et al. (2005). Optimization of virulence functions through glucosylation of Shigella LPS. Science 307, 1313-1317. doi: 10.1126/science. 1108472
Conflict of Interest Statement: The authors declare that the research was conducted in the absence of any commercial or financial relationships that could be construed as a potential conflict of interest.

Copyright (c) 2018 Kim, Moon, Kim, Rho, Shin, Song, Walker, Czerkinsky, Kim and Kim. This is an open-access article distributed under the terms of the Creative Commons Attribution License (CC BY). The use, distribution or reproduction in other forums is permitted, provided the original author(s) and the copyright owner(s) are credited and that the original publication in this journal is cited, in accordance with accepted academic practice. No use, distribution or reproduction is permitted which does not comply with these terms. 